\title{
Some Problems on Erozon Protection of Soils in Azerbaijan
}

\author{
Z.H. Aliev* \\ Institute of Soil Science and Agrochemistry of ANAS, Russia \\ *Corresponding author: Zhaliyev, Institute of Soil Science and Agrochemistry of ANAS, Russia
}

\section{ARTICLE INFO}

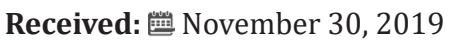

Published: 慧 December 09, 2019

Citation: Z H Aliyev. Some Problems on Erozon Protection of Soils in Azerbaijan. Biomed J Sci \& Tech Res 23(4)-2019. BJSTR. MS.ID.003941.

Keywords: Inclination Slopes, Forest-Land Reclamation, Terrace, Water Erosion, Surface Erosion, Erosion, Erosion, Environmental Conditions, Strips, Etc.

\begin{abstract}
ANNOTATION
$430 \mathrm{mkn}$. ha of land has been damaged by erosion processes in different countries around the world. Surface, cleavage and irrigation erosion is also widespread throughout the country. $43.29 \%$ of the total area is subjected to varying degrees of erosion. In some regions, especially the Nakhchivan AR, erosion processes cover $70 \%$ of the area. 66.6 of the total area of the southern slope of the Greater Caucasus has been eroded. In some areas of the country, the percentage of eroded farms is high. This Figure 1 is $51 \%$ in Lachin-Kalbajar zone, $57.9 \%$ in Guba-Khajmaz zone and $72.4 \%$ in Sheki-Zagatala. The newly formed splinters break down the farmland into small parts and make them useless. The following erosion intensity scale is presented. 1) net wash-up to $0.5 \mathrm{t} / \mathrm{ha}$, 2) poor wash-up to $0.5 \mathrm{t} / \mathrm{ha}, 3$ ) moderate washing 1-5 $\mathrm{t} / \mathrm{ha}$, 4) severe washing -5-10 $t / h a, 5)$ very severe washing $-10 t /$ ha. Different geographical areas of the country have also been identified the possible distances between stripes on different slopes. Soil preparation should be carried out with a strip of 1-2 $\mathrm{m}$ in every 3-5 $\mathrm{m}$ in areas of 10-200 incidence, moderate to severe, and 1.5-3 $\mathrm{m}$ wide in each of the 2-3 $\mathrm{m}$ in severely washed areas of 20-300 m. trench to be dug. In large areas with more than 15-200 thick, thick soils and where the tractor can operate, deforestation should be carried out on terraces. On the slopes where heavily washed and often rigid rocks are exposed, soil preparation can be used to make yards and ditches.
\end{abstract}

\section{Introduction}

Significant increases in agricultural productivity and sustainability are required to meet the population>s demand for food and agricultural raw materials. For this purpose, it is important to implement comprehensive measures to increase soil fertility, to apply intensive agricultural technology, and to carry out extensive anti-erosion control measures. The quantity and quality of agricultural products depends to a large extent on the availability of water in the fields. While irrigation water is not present in our country and in some cases, droughts are observed, some of the rain and snow, as well as irrigation water, are lost from the areas. As a result of erosion processes in various countries around the world, $430 \mathrm{mkn}$.ha of land has been destroyed. Surface, cleavage and irrigation erosion is also widespread throughout the country. $43.29 \%$ of the total area is subjected to varying degrees of erosion. In some regions, especially the Nakhchivan AR, erosion processes cover $70 \%$ of the area. 66.6 of the total area of the southern slope of the Greater Caucasus has been eroded. In some areas of the country, the percentage of eroded farms is high.

For example, this Figure 1 is 51\% in Lachin-Kalbajar zone, $57.9 \%$ in Guba-Khajmaz and $72.4 \%$ in Sheki-Zagatala. The newly formed splinters break down the farmland into small parts and make them useless. The material from the ravines covers valuable planting areas and pollutes the wetlands. Amelioration measures against erosion provide for efficient regulation of surface runoff, improvement of soil water regime, maintenance of fertility level. The presented review examines the laws of soil washing, the formation of surface runoff, some theoretical and practical problems in erosion control. There are controversies in the issues under consideration. Therefore, these data are summarized for objective estimation. Irrigation erosion has not been addressed. 
The article uses the results of research conducted by the staff of the TAI "Soil Erosion" laboratory (former Institute of Erosion and Irrigation of the Academy of Sciences) [1-5].

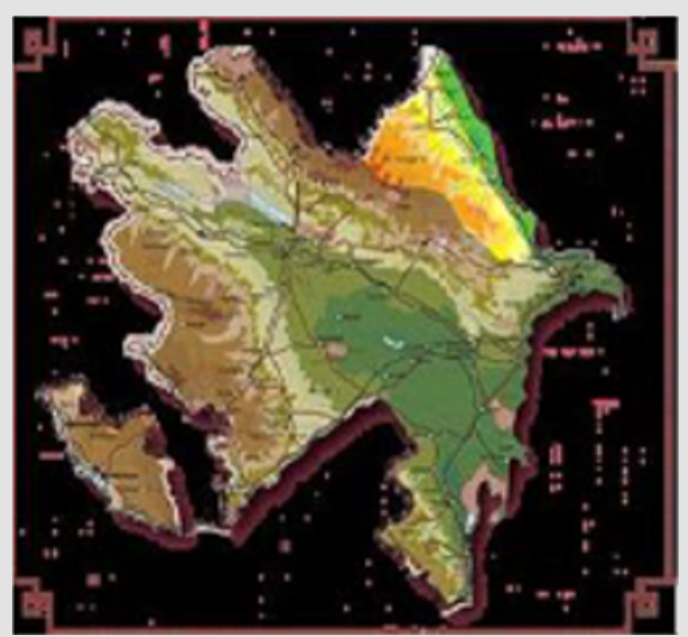

Figure 1: This figure is 51\% in Lachin-Kalbajar zone, 57.9\% in Guba-Khajmaz zone and $72.4 \%$ in Sheki-Zagatala.

\section{Scientific Bases of Protection of Soils from Water Erosion}

\section{Damages caused by the Erosion Process to the Environment and Agriculture}

Under the concept of water erosion, soil degradation is understood as the process of soil erosion and depletion through streams, as well as the processes of landscape degradation. Water erosion is the main cause of degradation of soils and natural complexes. Water erosion in nature occurs in two ways: surface erosion and (linear Argan) erosion. Surface erosion is not immediately apparent, especially at its initial stage. In fact, a 100 -acre area of $100 \mathrm{~m}$, an average width of $5 \mathrm{~m}$ and a depth of $2 \mathrm{~m}$ is formed in the area of one hundred hectares, and it does not go unnoticed. However, when washing $1 \mathrm{~cm}$ of soil from the area, this is hardly noticeable, although as a result of the development of that ravine, $10,000 \mathrm{~m} 3$ of valuable soil and soil are lost as a result of washing a 1-cm layer of 600-800 m3 and 100 ha. Therefore, surface erosion is much more dangerous. Washed areas every year cost $\$$ I million. Ha unused riparian areas increase by 100-150 thousand ha, and moving sands increase by 40-50 million ha. As a result of the erosion, the average annual soil incidence is $30-40$ tons per hectare and sometimes more. 2-3 billion tons of crop and sowing areas annually.

Soil, including 100 million tons of humus and 43 million tons of soil. Nitrogen, aosaor, potassium washed. This is 1.5 times more than the nutrients given to the soil in the form of mineral fertilizers. $22.3 \%$ of the forest areas of the country are below erosion of the AllUnion (4.5 ha) per capita area (0.2 ha) and are undergoing erosion.

Substantial changes in the microclimate characteristics of such areas occur, forests do not play a role in soil and water management, and after heavy rains there is a huge destructive flood. As a result of the erosion, $118400 \mathrm{~m} 3$ of soil enters the
Kishchai basin every year from the slopes. Suffice it to say that, based on archival documents, as a result of heavy mudslides in the Kish River basin on July 15, 1988, \$ 27 million was invested in the Sheki region>s businesses and businesses. b. damaged. In the mountainous meadows, which are used as summer pastures of the Republic, there is a rapid development of erosion processes due to overgrazing and overgrazing. As a result, the vegetation is deteriorating, its composition deteriorates, the soil structure and structure are disturbed and strengthened, and the surface is absorbed by surface currents without absorbing the soil. 80-91.2\% of summer pastures of Guba, Gadabay, Dashkesan, Khanlar and Sheki are affected by erosion and decreased productivity by 1.53.0 times. And changes in vegetation cover (deterioration of feed resources, etc.) will undoubtedly affect the wildlife, especially their migration, which is extremely sensitive to the environment. The foregoing proves that the intensive development of erosion affects agricultural production and the environment, and the development and implementation of effective anti-erosion measures are one of the most important areas of the day [6-10].

\section{Justification of Anti-Erosion Measures}

When developing erosion control measures, the intensity of surface runoff and soil washing, erosion of eroded soils, etc. issues are taken into consideration. The goal here is to create conditions to prevent surface formation in the upper slopes of the slope. If this cannot be prevented by existing means, it is intended to store particles in the required area of the soil to prevent excessive washing of fine soil particles. Various modeling methods have been used for this purpose in recent years. Examples of these are simple mathematical models (a map of washed soils, etc.). Predictive issues are used to justify soil conservation measures. The universal equation proposed by American scientists can be widely used to predict soil loss. The washed lands are allotted to justify the system of countermeasures, to maintain and increase the fertility of the lands. In order to characterize the general washing of soils in the area of cultivation slope, in the area, it is recommended to calculate the recommended average soil washout index (Pop) by the following formula:

$$
\text { Pop }=\left(\left(P_{-}\left(1 S_{-} 1+\text { P2S2 }+ \text { P3S3 }+\cdots . .+ \text { PnSn }\right)\right)\right) / 100
$$

Here, Pop is the average soil wash indicator, P1, P2, P3 and so on. The amount of soil contour washing elements is S1, S2, S3 and so on. elements are the area of the soil contour. If, as a diagnostic indicator of soil washing, the humus content in the $0-50 \mathrm{~cm}$ layer is taken down, then P1, P2, P3 should represent the amount of humus in the $0-50 \mathrm{~cm}$ layer. A universal equation evaluation of erosion processes is not enough. The Australian National University uses cesium adsorbed by soil particles to map eroded soils. In the former SSPI, the allowable washing threshold for black soils ranges from 3 to $5 \mathrm{t}$ per hectare. However, it is considered that the maximum allowable amount of soil washing for Azerbaijani conditions should not exceed 0.2-0.5 t. So much of the loss of land itself is not 
compensated for by the increase in the fertility of such lands. The following erosion intensity scale is presented. 1) slight wash-up to $0.5 \mathrm{t} / \mathrm{ha}, 2)$ poor wash-up to $0.5 \mathrm{t} / \mathrm{ha}, 3)$ moderate washing 1-5 t/ ha, 4) severe washing -5-10 t/ha, 5) more severe washing -10 t/ha.

\section{Complex Anti-Erosion Measures on Slopes}

Integrated anti-erosion measures include economic, organizational, agrotechnical, meadow, forest and hydromeliorative measures. Implementation of these measures should at the same time prevent the negative impacts of all natural and economic activities and provide an opportunity to increase the productivity of their lands.

\section{Organizing the Area as an Important Part of Erosion Control}

Anti-erosion of the area, composition and proportions of agricultural sector, measures for its productivity increase, types and types of crop rotation, number of farmlands, alternate plantings, hydrotechnical constructions, forest strips, boundary and settlement, volume of agricultural works. identifies issues. For this purpose, a general scheme of anti-erosion management of individual farms, administrative regions, provinces and the country are being developed. Land use projects designed for individual farms have greater practical significance. Such projects in our country are designed for a maximum of $1: 10000$ and partly 1 : 25 000. While drafting an erosion control area for the area. First, natural conditions are analyzed. To this end, the Agroecological Science Center has carried out relevant research in almost all mountainous and foothill areas of the country, and maps of soilerosion maps and cartograms, erosion factors and anti-erosion measures. Intermediate cultivation should be preferable on slopes with 5-60 slopes prevailing on untreated and poorly washed soils, and cereal crops on 6-120 slopes.

At the end, inter-row vegetation should be $20-25 \%$, perennial grasses $30-40 \%$. Soil protection should be widely used on moderate to moderately severely sloping $12-150$ slopes (in moderately washed soils), and in areas with heavy washes should not be used as natural cuttings. The low efficiency of anti-erosion organization of the area is mainly due to the poor location of road and forest strips within the boundaries of arable land. In most cases, the linear elements shown are arranged in such a way that they move up and down the slope. This results in the accumulation of surface currents along slopes, roads and other structures and the rapid development of erosion processes. The longest sides of the cultivated areas must be in the direction of the slope to effectively prevent surface currents. Project development begins with the identification of more feasible areas of specialization of the farm, considering soil erosion protection. Based on a detailed study of natural conditions, alternate plantings, crop erosion technology, fertilizer system development, sloping and other useless areas, development of erosion forest planting and hydraulic engineering structures, roads, etc. are developed. Several farms in the country have begun to use contour-reclamation systems to prevent erosion and increase productivity by regulating surface flows. This system assumes that all plowing and cultivation works are carried out in accordance with relief horizons, creation of water-retaining and retaining pillars and dams on erosion-prone areas and on the outskirts of farms, laying of wood strips on the edges, special agrotechnical measures.

\section{Phytomeliorative Measures with the Participation of Hydraulic Devices}

Anti-erosion agro-melioration-erosion is an engineeringbiological system. Protective forest strips and hydrotechnical anti-erosion facilities are the main elements of this system. Forest plantations cause both surface and internal streams to leak into the soil and retain most of the biogenic elements. The number of biogenic elements decreases by 4-5 times in the surface flow of the forest strips in the sown areas. The number of nitrates in the water released from the livestock complexes at this time is 23 to $4.2 \mathrm{mg}$ / kg. l, nitrites decrease from 1.42 to $0.12 \mathrm{mg} / \mathrm{l}$, and phosphorus by 1.5 times. All this prevents pollution of surface and inland water and water sources. Protective forest strips are often used in conjunction with simple hydrotechnical installations to enhance the erosion efficiency. A trench forest strip with a depth of $0.6 \mathrm{~m}$, a depth of 1.2 $\mathrm{m}$ and a depth of $0.1 \mathrm{~m}$ between the bottom line retains almost all of the surface runoff from the basin. In the North Caucasus, faulting surface fluxes decreased 6-8 times. The last century from the 1970s on the southern slopes of the Greater Caucasus, erosion was carried out in the field with various soil preparations (pitch, trenches, stripes) and their impact on soil washing.

At that time, 18785 tons of land was washed out of each hectare under control (non-forest planting area), a total of 955 and 2210 $\mathrm{g}$ of soil were washed out of the area prepared by pitch and strip method. One of the most important principles for the creation of forest strips is their proper slope or slope placement. The distances between stripes along different slopes are also determined for different geographical zones of Azerbaijan. Soil preparation should be carried out with a strip of 1-2 $\mathrm{m}$ in every 3-5 $\mathrm{m}$ in areas of 10-200 incidence, moderate to severe, and 1.5-3 m wide in each of the 2-3 m in severely washed areas of $20-300 \mathrm{~m}$. trench to be dug. In large areas with more than 15-200 thick, thick soils and where the tractor can operate, deforestation should be carried out on terraces. On the slopes where heavily washed and often hard rocks are exposed, soil preparation can be used to make pitch and trenches. Forest-amelioration measures are used to strengthen the ravines and caves. For this purpose, trees and shrubs are planted on their edges, slopes and bottoms, with a strong root system and root-bearing ability that does not require moisture and soil fertility. In this case, depending on the inclination and soil conditions, it may be more beneficial to carry out soil preparation on the slopes and slopes, with terraces, pitch, trench and slabs, and pitch and bare. In almost all gardening areas, the use of simple hydraulic rigs, trenches, splinters and cracks is more efficient. 
They function more efficiently when filled with stalks, manure, and organic sheets. In the gardens located on the slopes (12-140), spraying intervals play a positive role. Most of the summer and winter pastures in our country need serious surface and major improvements. Improvement in the mowing and cutting should be carried out in a comprehensive manner. At the same time, simple hydraulic structures (water supply and retaining dams, poles, etc.) are not only aggravated by agrotechnical measures (strip plowing, buffer stripes, cleavage, etc.), but the main role is to prevent and wash the soil. m Reclamation (perennial grass planting) should be provided, cultural pastures and weeds should be created.

\section{Land Reclamation}

In the mountainous and foothill areas of the republic there has been an intensive development of erosion, which is one of the most dangerous and destructive types of soil erosion in recent years. Over the past ten years, the area of the unused flea in our country has grown by more than 5 million tons. 6.6 million ha of acreage. Their length reached 1 million $\mathrm{km}$, and their total number reached 13 million. As a result of the development of the ravines, the area of the farmland grows by 100-150 thousand hectares annually. Recently, new methods for the recultivation of crushed areas in the agricultural sector of the country and abroad have been widely used. This fight involves partial or complete replenishment of the slopes with the preservation of the upper soil fertility, or their slopes filled with the tendency for agricultural plants to develop, allowing machines and mechanisms to function. Fundamental land reclamation should be based on a pre-recorded project. The fill slope is divided into individual areas of 20-25 meters depending on the total length. The amount of land works is calculated based on the size of the ridge (width, length, and depth).

It is then decided whether the project orientation will be chosen - the extent to which the inclination of the slope to be completed is appropriate. Subsequently, $30-40 \mathrm{~cm}$ deep or waterlogging soil dams are created at 2-5 $\mathrm{m}$ from the head of the ravine to prevent surface runoff from entering the reclamation area. Then the filling of the fleet is started. Bulldozer, credit, it can be used as landing machines such as sniper and excavator. The bulldozer first peels off the three fertile humus layers from the first area of operation, and this section is filled to the required depth. Then the bulldozer moves to the second area of the first area, moving the humus layer to the surface. The second area is filled with brass. Work in other areas is followed in the same sequence. Perennial grasses are being planted in the area to protect the smoothed area from further erosion effects and the areas will be used for 2-3 years. Soils are given high doses of organic and mineral fertilizers. It is advisable to apply for slopes with relatively soft clays with water depth of not more than 5-10 hectares located on slopes of 10-150 with a length of 300-450 $\mathrm{m}$ and average depth of 5-7 m. The implementation of these measures in our country each year will help to obtain a significant amount of additional land at the expense of useless soils and to protect the most valuable natural resources.

\section{Interactions of Elements of Complex Measures of Struggle}

Erosion control is a complex, labor-intensive process that requires the implementation of complex measures: economic, organizational, agro technical, phytomeliorative and hydrotechnical. Due to the protective conditions of protective plantings and hydraulic facilities, it is necessary to be in accordance with the contour-reclamation principles. When the area is organized on a contour-reclamation basis and the complex measures are implemented, agrolandshafts approach their natural stability to almost all atmospheric sediments. The interaction between the elements of the soil protection measures is quite high. For example, a shaft-terraced wooded strip, reinforced by ditches in the form of an interconnected system, completely engulfs atmospheric sediment within 5 years. Soil protection systems are also preferred in many countries around the world. However, the application of scientific research in our country does not meet the requirements of soil protection. Soil seeding is poorly utilized, forest planting is not carried out on a large scale, and some parts of the planted lands cannot perform their role due to poor maintenance. Simple hydraulic devices are used on such a small scale. One of the main reasons for this is that the erosion process is sufficiently accurate to estimate the actual damage caused to the environment, its pollution, and the lack of a unified methodology. It is important to determine the optimal rates of planting, meadow, grass and forest areas depending on local soil-climatic conditions to successfully combat erosion. Environmental and land protection services should be established to ensure compliance with established standards, and enough staff should be provided. Interest in the protection and preservation of the land should also be increased. Soil protection and fertility should be a key criterion for evaluating the activities of farm managers and specialists.

\section{Conclusion and Offers}

In recent decades, the intensification of erosion processes has been attributed to the decline of humus in the soil, deterioration of the water-physical properties of soils, and inadequate antimicrobial activity of humans. Water erosion has taken such a scale that if it continues this way, $1 / 3$ of the agricultural land in our country could fall into disrepair in 20 years. To justify erosion measures, erosion processes have been studied and possible land losses have been identified. Different modeling methods, empirical equations, new methods of mapping and classification of eroded soils have been proposed. All this allows designing of anti-erosion complexes based on calculation. Successful solution of the water erosion problem is possible only with the use of a complex of soil protection measures, which are interrelated and complementary economic, organizational, agro, forest, meadow and hydromeliorative 
measures. The following are important for the solution of the problem of soil erosion protection:

1. norms should be adopted to determine the relative areas of planting, meadow, grass, water and forests in accordance with local soil-climatic and economic characteristics.

2. An environmental service should be established to monitor compliance with established standards.

3. Specific norms of optimal ratio of economic areas (as well as forests) as a basis for sustainable agriculture for each zone should be determined by the interaction of elements of the complex must be defined;

4. The soil fertility balance for 10-15 years should be determined. This enables to control the use of sown areas, to consider the environmental consequences of economic activities, and significantly increases the responsibility for the preservation and protection of land resources.

\section{ISSN: 2574-1241}

DOI: 10.26717/BJSTR.2019.23.003941

Z H Aliev. Biomed J Sci \& Tech Res

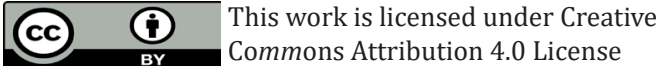

Submission Link: https://biomedres.us/submit-manuscript.php

\section{References}

1. Alekperov KA (1961) Soil erosion in Azerbaijan and measures to combat it. Baku Science.

2. BH Aliyev, AA Irahimov (2001) Modern state of erosion process in Azerbaijan and system of measures to combat it (scientific-methodical instructions). Baku p. 98

3. Allen R Roth (1983) How to Speed M Misl pp. 148.

4. Buyakin NI Mukhamedzhanov (1985) VI Mailing Addresses for Post Offices. Emerald p. 41-43.

5. Dubinsky SP, Buryanov (1985) VI Farmhouse agribusiness. Kharkov 216.

6. Zaslavsky MN, Larinov GA, Litvin LF (1984) Mechanisms and laws of the erosion process. Sat Erosion process. M Misl p. 31-48.

7. Zarudny YK (1985) Lesbian Pumps with Valleys. Attempt 2: 42-44.

8. Zaslavsky MN (1983) Erosion M High School pp. 320.

9. Rozhkov AG (1975) Boring with the USSR and the Russian Federation M p. 37.

10. Mitchell JK, Bubenzer GD (1984) Calculation of mailboxes. Sat M Colos p. 34-96.

$\begin{array}{ll}\text { BIOMEDICAL } & \text { Assets of Publishing with us } \\ \text { RESEARCHES } & \text { - Global archiving of articles } \\ & \text { - Immediate, unrestricted online access } \\ \end{array}$

